\title{
IMPRENTAS, TiPÓgRAFOS Y ESTILOS DE VIDA en el Caribe Colombiano, 1850-1930*
}

\author{
Por: Sergio Solano De Las Aguas
}

Artículo Recibido: Abril 29 de 2008

Artículo Aceptado: Junio 25 de 2008

\section{RESUMEN}

En este artículo se analiza la importancia del oficio de la tipografía bajo el contexto de la república, su papel en determinar un estilo de vida organizado en torno al honor, la dignidad, la valoración de la educación y del trabajo. También se discute como ese estilo de vida era compartido por otros sectores laborales, proponiendo la tesis de la existencia de unas capas medias de los oficios rudos organizada en torno a un estilo de vida que giraba alrededor de la dignidad personal y familiar.

Palabras Claves: Tipógrafos, artesanos, estilos de vida, honor, capas medias.

\section{ABSTRACT}

This article discusses the importance of the craft of typography in the context of the republic, its role in buildin-g a lifestyle organized around the honour, dignity, valuing education and labour. It also discusses how this lifestyle was shared by other industrial sectors, suggesting the thesis about the existence of layers average trades rudos organized around a lifestyle that revolved around the personal dignity and family.

Keywords: Typographical, lifestyles, honour, middle layers.

\section{Presentación}

Entre las innovaciones introducidas en el mundo del trabajo manual de la región Caribe colombiana durante el largo siglo corrido entre 1850 y 1930 sobresalieron la tipografía y la mecánica. Surgidos en la época moderna, el impacto que tuvieron en las transformaciones que ha vivido el mundo ha sido develado por las investigaciones sobre la revolución industrial inglesa de finales del siglo XVII, y por las indagaciones sobre la cultura moderna basada en la grafía impresa, campos 
de lo que representan buenos indicativos lo llevado a cabo por la historiografía social inglesa y por los estudios de los franceses sobre las formas de sociabilidad cultural y política, el desarrollo de la vida privada y las transformaciones de las jerarquías de los sentidos. ${ }^{1}$

Hija del siglo XV, sólo en las postrimerías del período colonial la imprenta fue introducida en el Nuevo Reino de Granada, siendo Cartagena la segunda ciudad del país en que se instaló después de Santafé de Bogotá. ${ }^{2}$ Su consolidación se dio en el siglo XIX gracias a las condiciones de tolerancia cultural y política que la república inauguró, creando dos escenarios para el desenvolvimiento de la libre argumentación: la plaza pública y la palabra impresa (libros, folletos, pasquines, periódicos, carteles murales, revistas, etc.). Estos escenarios connaturales a la política moderna a su vez fueron transformando las modernas nacientes, formas de sociabilidad cultural y política (tertulias, clubes y partidos políticos, sociedades populares de corte jacobinas, asociaciones científicas, etc.), al lograr que perdieran el carácter de círculos de iniciados, ampliando sus esferas de influencias, aún entre sectores de iletrados. Estas circunstancias otorgaron a la tipografía unas connotaciones culturales y sociales singulares entre todos los oficios artesanales que se ejercían.

¿Qué novedad representó la tipografía en el contexto de los oficios artesanales? ¿qué llevó a personas de diversa condición social a dedicarse a este oficio? ¿socialmente homogenizaba este arte a las personas que lo desempeñaban? ¿cómo se aprendía? ¿qué aporte hicieron los tipógrafos al desarrollo de la cultura artesanal? ¿ese estilo de vida era patrimonio exclusivo de los tipógrafos o también estaba presente en otros sectores sociales? Estos son algunos interrogantes que pretendemos responder en este artículo.

\section{Imprentas e Impresores}

La primera imprenta introducida en Cartagena fue la del Real Consulado de Comercio, creado en 1794 por iniciativa, entre otros de José Ignacio de Pombo, acaudalado comerciante y hombre ilustrado de esta ciudad portuaria. En esa imprenta, entre 1808 y 1810 se editó el periódico Noticias Públicas de Cartagena de Indias del que salieron a la luz pública 140 ediciones. Una vez triunfó la república el número de imprentas en la región Costeña durante el siglo XIX fue creciendo, dedicadas a imprimir una significativa cantidad de periódicos, en su mayoría de vida efímera. Durante esa centuria, en la ciudad de Cartagena aparecieron 212 títulos, seguida por Barranquilla con 93, Santa Marta con 88, Riohacha con 
22 y Mompox con 13 (sin incluir cantidades menores en otras poblaciones de esta región), número crecido, pues si excluimos a la capital de la república (en la que se editaron 880 títulos), en comparación con el resto de regiones del país los títulos de la Costa representan el 53\% del total nacional. Luego, entre 1910 y 1928 en el departamento de Bolívar, excluyendo al actual Atlántico separado en 1905, se editaron 322 publicaciones periódicas, correspondiendo a Cartagena 132, seguida por Magangué con 35, Sincelejo 27, Mompox 21 y Montería 19. También circularon periódicos locales en pequeñas poblaciones como Lorica con 12 periódicos, Chinú 8, San Marcos 4, Calamar 8, Sucre 7, Corozal 5, Sahagún 3, El Carmen de Bolívar 7, Tolú 4, Cereté 3, Ciénaga de Oro 2, Villanueva, Arjona 4 y con un periódico aparecen San Pelayo, Pinillos, San Estanislao, Tolú Viejo, Bodega Central, San Antero, Margarita, Sampués, Sincé, Ovejas, Turbaco. ${ }^{3}$

Durante la primera mitad del siglo XIX sobresalieron las tipografías de Juan Antonio Calvo (la primera referencia sobre ella es de 1813 y en 1852 Bartolomé Calvo la trasladó a Panamá), la de Francisco de Borja Ruiz (primera referencia de 1826, perdurando hasta 1912 cuando sus descendientes la vendieron al poeta Luís Carlos López), Tipografía Tormentaria de José María Angulo (primera referencia de 1829 y en 1840 se pierde su rastro), la de Manuel María Guerrero (primera referencia en 1830 y después aparece en Santa Marta, al lado de su sobrino, el tipógrafo Antonio Locarno Mandrecha) y la Imprenta de Eusebio Hernández y Valdés (referenciada por vez primera en 1831 y a la vuelta del siglo XX se unió con la de los Ruiz, perdurando hasta el decenio de 1970). Aparte de Cartagena, durante esa media centuria sólo Mompox contó con una tipografía, la de Manuel Locarno Guerrero, en la que se editó un periódico en 1817, y Santa Marta con la del Seminario (referenciada por vez primera en 1831), la Gaceta Mercantil de Manuel Murillo Toro (1847) y la de Antonio Locarno (referenciado por vez primera en esta ciudad en 1835), quien en 1852 se trasladó a Barranquilla. ${ }^{4}$

En la segunda mitad de ese siglo, el número de imprenta y de publicaciones periódicas creció debido a la encarnizada vida partidista y a que se ensanchó el imaginario ilustrado que concebía el adelanto del país y de la región como un resultado del avance de la educación y de la cultura. En 1875 había en Cartagena 3 tipografías (Antonio Araujo L., Hernández e Hijos y Ruiz e Hijos); once años después este número creció a 8 talleres (además de los anteriores, los de Donaldo E. Grau, Osvaldo García e Hijos, Federico Núñez, Justo R. Villarreal y la del Colegio Araujo). En 1912 existían 11 talleres (además del de Araujo, Villarreal, la del Colegio Araujo -que cambió de nombre por El Esfuerzo- y Ruiz y Hernández, estaban El Penitente, Mogollón, Domingo de la Espriella, El Renacimiento, La 
Patria, Virgen de la Popa y El Centenario). En Barranquilla en 1897 había seis imprentas (Americana, Los Andes, El Anotador, Diario Comercial, El Comercio y El Progreso) y en 1910 ya eran siete. ${ }^{5}$ Con excepción de la imprenta Araujo y la de Mogollón (que llegó a ser la más grande de Colombia con sucursales en varias ciudades en la primera mitad del siglo XX), las que en el período finisecular renovaron sus equipos, utilizando fuerza a vapor en sus prensas, dándoles una mayor rapidez en las impresiones, el resto de las imprentas eran pequeños talleres manuales cuyas prensas eran movidas por fuerza humana.

El trabajo en el taller tipográfico involucraba varias fases, iniciándose por el paciente trabajo del tipógrafo o cajista quien insertaba en el componedor las letras y signos de manera invertida para formar las palabras. Cada línea formada en el componedor era colocada en el galerín dando origen a las columnas; entre esta fase inicial y la impresión mediaban etapas intermedias, siendo las principales la distribución, la corrección de pruebas y de moldes. Contrario a lo que pueda parecer, la labor del tipógrafo era más artística que mecánica, pues se requería una concentración excepcional para reproducir un original sin erratas y darle belleza a la impresión mediante la escogencia de la forma y tamaño de los tipos (cicerón, breviario, filosofía o entredós, misal y nomparell), viñetas y la distribución espacial del mismo. Pero sobre todo, el tipógrafo debía poseer una buena formación cultural para que entendiera lo que reproducía y para que desempeñara la función de corrector, utilizando los signos de Giráldez. ${ }^{6}$ Una vez que se levantaba un texto, se hacía una impresión de prueba y esta pasaba a manos del corrector oficial (esta función la mayoría de las veces la desempeñaba el jefe de redacción de la publicación periódica o el autor del libro), persona que debía poseer una cultura superior a la del cajista porque su función requería de responsabilidad e infinita capacidad de concentración. Del buen desempeño del cajista y del corrector expresado en lo impecable de la impresión, dependía el crédito de la imprenta entre el público. En el trabajo de impresión intervenían, además de los anteriores, los prensistas, personas con fuerza muscular para mover las prensas.

El número de personas ocupadas en las imprentas siempre fue bajo dado que los dispositivos mecánicos exigían poco mano de obra y no existía una clara diferenciación técnica del trabajo, pudiendo una misma persona desempeñar varias ocupaciones. Además, el jefe de redacción no se distanciaba de los tipógrafos. Según un informe oficial, en 1924 las tipografías existentes en Cartagena (Imprenta Departamental, Araujo L., J. V. Mogollón y Cía., Carlos Escallón, Penitente, El Anunciador, El Liberal, A. Hernández G.), ocupaban un total de 71 operarios. En Barranquilla, en 7 imprentas que había en 1910 trabajaban 31 tipógrafos. $^{7}$ 
El montaje de las tipografías corrió a cargo de individuos de diversa condición social, que importaron pequeñas máquinas o compraron otras muy usadas, estimulados por las expectativas diversas que se abrieron con la creación de nuevos espacios y formas de sociabilidad culturales y políticas bajo la república, como también por lo cautivante del oficio. Una mirada sobre casos particulares nos permitirá ver las vías de llegada a la tipografía y las posibilidades de ascenso social.

En los años diez del siglo XIX Juan Antonio Calvo, quien había trabajado en la imprenta de Diego Espinosa de los Monteros (la primera que existió en Cartagena), estableció un taller tipográfico, con características de empresa familiar. En ella, su hijo Bartolomé Calvo (nacido en 1815) aprendió el oficio de tipógrafo, y al fallecer su progenitor se vio obligado a abandonar los estudios de jurisprudencia para consagrarse al oficio, y en el año de 1848 creó el periódico La República, de inspiración conservadora, que el mismo redactaba, componía y tiraba en la imprenta heredada de su padre. ${ }^{8}$ En este caso, un arte aprendido con anterioridad a la exacerbación de las luchas partidistas sirvió para agenciar un proceso de movilidad social de una familia que antes de eso no aparece en los registros escritos.

Manuel Locarno Guerrero, fue la persona que introdujo la imprenta en Mompox en 1817. Su padre salió exiliado a Jamaica después del sitio de Morillo en 1815 y allí conoció la imprenta y la trajo consigo cuando regresó en 1821. ${ }^{9}$ Su tío materno, Manuel María Guerrero (nacido en Cartagena en 1785, militar del regimiento fijo en 1800, y quien llegó a ser coronel de la república) también contó durante los años de 1820 con una imprenta en Cartagena, y el hijo del primero Antonio Locarno Mandrecha introdujo la imprenta en Santa Marta en 1835 y luego lo hizo en Barranquilla en 1852.

Otro caso es el de Antonio Araujo León (nacido en 1852), hijo del doctor Manuel Joaquín Araujo Sáenz y de Carmen León Baquero. En esta familia sobresalieron médicos, abogados, farmaceutas y pedagogos, y para la época en que nuestro tipógrafo estaba en su pubertad, era una de las familias más prestantes de la ciudad de Cartagena lo que hacía suponer que aquél se dedicaría a una de las profesiones liberales que se estudiaban en la Universidad de esta ciudad. Sin embargo, una pequeña semblanza biográfica realizada en 1912, nos presenta a Antonio Araujo muy inclinado desde temprana edad a los gajes del oficio de tipógrafo, utilizando una pequeña prensa manual que había en su casa. En 1872, ayudado pecuniariamente por sus familiares, compró a José María Pasos (hijo) 
una pequeña imprenta, en la que al mismo tiempo encuadernaba y vendía libros. El caso de este personaje es singular dentro del gremio de los tipógrafos dado que incursionó en muchos otros terrenos (política y administración pública), alcanzando el grado de general durante la guerra de 1885. Dado que llegó a tener la imprenta más importante de Cartagena a finales del siglo XIX, editando el periódico El Porvenir, tribuna del movimiento regenerador y de Rafael Núñez, en él se nota un esfuerzo por distanciarse del gremio de los tipógrafos, llamándose a sí mismo impresor (en 1875 aparece en los listados de impuesto directo sobre la renta como tipógrafo y en el censo poblacional y ocupacional de ese mismo año como artesano), pero manteniendo su ascendencia social y política sobre aquellos. Qué llevó a Antonio Araujo a un oficio que en la época en que compró la imprenta era aún incierto en sus recompensas materiales? Es difícil saberlo, pero sin duda alguna que esa inclinación de pequeño y el formar parte de una familia letrada hubo de influir en ello. A más de ello, José María de León Baquero, su tío materno, también ejercía ese oficio para finales de dicha centuria. ${ }^{10}$

Un tercer caso es el de Federico Núñez Romero y Domingo González Rubio (nacidos en el barrio de Getsemaní en 1832 y amigos desde la infancia, militantes del liberalismo y de logias masónicas), casado el primero con una hermana del segundo. En 1848 el primero compró una pequeña imprenta y ella comenzó a editar el periódico La Democracia, constituido en el vocero del liberalismo de mediados del siglo XIX. Es muy probable que en esta imprenta haya trabajado Domingo González Rubio, quien en 1856 se trasladó a Barranquilla y en 1872 empezó a dirigir el periódico El Promotor, fundado por el bogotano Ricardo Becerra. Cinco años después era el propietario de dicha imprenta. Un hijo de Federico Núñez, llamado por el mismo nombre, también desempeñó el oficio de la tipografía y después se dedicó a la pedagogía. Aquí estamos frente al hecho de una familia que se especializa en el oficio.

Situación similar a la anterior es la de Francisco de Borja Ruiz y Eusebio Hernández y Valdés; ambos en 1831 formaban parte de la Sociedad de Veteranos Defensores de la Libertad, apareciendo el primero como capitán y Contador General del Hospital y el segundo como impresor. Ruiz, según un censo del barrio de La Catedral levantado en 1851, era impresor, dando origen a una familia que ejerció el mismo oficio hasta comienzos del siglo XX. El segundo, hijo del patriota getsemanisense Lorenzo Hernández, quien en 1815 se trasladó a Haití y allí conoció la imprenta ${ }^{11}$ fue la matriz de una familia consagrada al mismo arte hasta bien avanzado en siglo XX. Para esta época, estas familias unieron sus pequeños talleres para poder afrontar la competencia de otras imprentas que 
contaban con mejores equipos.

Casos muy singulares fueron los de Gabriel E. O’Byrne Carrillo, Lácides Segovia y Juan Coronel Galluzo, nacidos en 1858, 1868 y 1859 respectivamente. O’Byrne, huérfano de padres a temprana edad, fue criado por la madre de Juan Coronel; autodidacta cultural, desde muy joven se vio obligado a trabajar. Su cultura le permitió acceder al oficio de corrector de prueba en la tipografía de A. Araujo L., y allí aprendió todo lo relacionado con el oficio. Después que Rafael Núñez se posesionó de la presidencia en 1886, O’Byrne pasó a desempeñar el cargo de redactor de El Porvenir. Políticamente fue conservador. El mulato Juan Coronel G., hermano de crianza de aquél, también fue un autodidacta cultural guiado por éste. Después de trabajar en la fábrica de Fósforos de los Jaspe y luego en una casa comercial, ingresó a laboral en la imprenta Araujo y allí aprendió el oficio de cajista, el que continuó desempeñando en Venezuela, Puerto Rico, Guatemala, Ecuador y Chile, país en el que murió en 1904. Políticamente fue un liberal radical. Lácides Segovia, también de origen humilde y huérfano a temprana edad, le tocó trabajar duro para salir adelante. Antes de cumplir los 20 años se desempeñó como portero de la Secretaría de Hacienda del Estado de Bolívar; incursionó en política ganándose el aprecio de la dirigencia del conservatismo (Joaquín F. Vélez y Manuel Dávila Flórez). Ocupó varios cargos públicos, y cuando su partido cayó en desgracia, después de la guerra de 1876, al quedar cesante tuvo que acudir a la imprenta Araujo en la que comenzó a ejercitarse como encuadernador y allí trabajó este oficio durante 5 años. En dicho taller también aprendió todos los avatares del oficio de la tipografía. ${ }^{12}$

Germán Maciá también fue otro tipógrafo que se inició en el oficio desde temprana edad, arte en el que, ... debido a su inteligencia y a sus grandes esfuerzos se hizo hombre de sano criterio y de conducta intachable. Trabajó incansablemente para conseguir el engrandecimiento de la enseñanza en las artes a todo aquél que tuviera la voluntad de ser su discípulo. También resaltó lo que debía al oficio: Desde mi aprendizaje hice del arte una especial distracción a mi vida, no sólo como medio de recursos para la lucha por la vida, como de escuela y algo más que mis pocas facultades literarias no alcanzan a nombrar... ${ }^{13}$ Estos cuatro casos representan a gentes

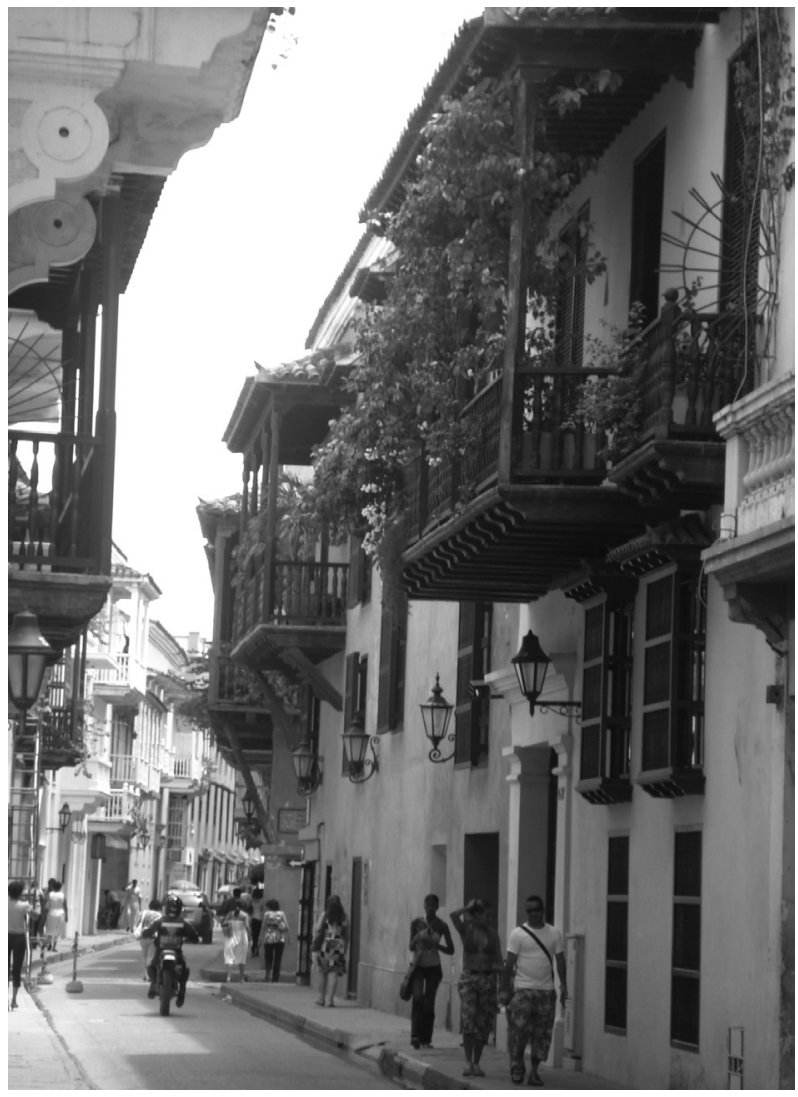


provenientes de la estrechez económica, quienes basados en sus propios esfuerzos culturales y quizá en sus relaciones políticas (sustentadas en una estima por dicha condición cultural), se dedicaron al oficio que aquí comentamos.

La vida de Aurelio de Castro en Barranquilla posee una singular importancia por sus iniciativas en pro de la organización artesanal y obrera a comienzos del siglo XX. Nacido en Barranquilla en 1864, estudió en el Colegio Caldas cuando éste era dirigido por el liberal radical venezolano Pedro Sederstrong, y luego continuó estudios en los Estados Unidos. A los 19 años combatió en la guerra civil de 1885 en las filas del conservatismo, y un año después fue elegido diputado a la Asamblea del naciente departamento de Bolívar. Entre 1890 y 1891 editó en la imprenta de su tío el liberal José M. de Castro, el periódico La Verdad; después fundó varios periódicos y en 1909 adquirió una imprenta y empezó a editar El Pueblo, periódico desde el cual propugnó por la organización artesanal y obrera. ${ }^{14}$

Los esbozos biográficos anotados a primera vista presentan a un conglomerado social heterogéneo, debido a los diversos caminos de llegada a la imprenta, a las posibilidades de diferenciación social, y por las posiciones políticas dispares, etc. Sin embargo, por encima de esas diferencias hubo muchas afinidades, las que unían a los tipógrafos a través de imaginarios, redes de solidaridad, principios de autoridad, proyecciones de imágenes frente a otros grupos laborales y culturales, etc.

\section{La Prestancia del Oficio, Estilo de Vida e Intentos de Reformar la Cultura Popular}

La publicación impresa otorgó a quienes realizaban la parte mecánica e intelectual del oficio una autoestima y una consideración social de grandes proporciones debido a que el imaginario ilustrado que la acompañaba resaltaba el papel de la educación y de la cultura en la realización del progreso, aspiración que se contraponía al contexto cultural existente visto como el reino de la oscuridad, de lo bárbaro y de la ignorancia. Muchos de los partidarios de este imaginario fueron atraídos por la imprenta independientemente de sus condiciones sociales, y una vez en contacto con ella les fue difícil huir de su encanto. El escritor al ver la materialización de su creación mental, y el tipógrafo sintiéndose un pequeño Dios que le daba forma, tipo tras tipo, a lo que la mente humana producía. Escritor e impresor se sentían cómplices en la actividad creativa y el primero invadía los espacios de la imprenta para observar, corregir los levantes y las impresiones, y de ese diálogo surgían afinidades y consideraciones, las que fueron descritas así: Casi todos los escritores cartageneros han vivido entre chibaletes y rodillos. Los Calvos -Juan Antonio y Bartolomé-, los Royos -José Manuel y Cátulo-, Federico Núñez, Lázaro María Pérez 
y su hijo Joaquín María, Manuel C. Bello, Eusebio Hernández Torres, Camilo Delgado, Gabriel E. O'Byrne, Juan Coronel, Gustavo Maciá del Castillo y otros. ${ }^{15}$

El tipógrafo se consideraba un trabajador privilegiado al sentirse parte importante en la realización del progreso; Juan Coronel G., en 1894 escribió:

Mucho debe la humanidad al invento del hijo de Maguncia. Puede decirse, sin exagerar, que la imprenta es la madre de todos los progresos; la constante reveladora de los secretos que guarda el infinito cosmos, y el auxiliar imprescindible de la inteligencia. La imprenta vulgariza la verdad luchando contra la ignorancia...

Podemos considerar la imprenta como religión universal, a la que ofrenda el escritor las primicias de su cerebro, y el cajista los días más preciosos de su vida. [Después de señalar la poca valoración que de este último se hace, agrega]...Sin embargo, el cajista es importante operario en la urdimbre de las ideas que toman vida eterna al ser impresas. Esa inteligencia que se confunde en una con la del escritor; ese hombre que va pacientemente descifrando el sentido de las oraciones a veces desprovista de él, ese tiene su parte de gloria en los triunfos del día y el egoísmo se la arrebata, condenándole a la anonimidad, al hambre $y$ la vergüenza. ${ }^{16}$

Otro hecho que resalta en los testimonios es que los tipógrafos tenían en alta estima a la educación, siendo los talleres centros de sociabilidad cultural y política en los que se difundían y discutían las lecturas que circulaban de mano en mano. Juan Coronel nuevamente señala lo que debía al oficio de tipógrafo: El oficio de cajista -bendito sea!- que ejercí por más de ocho años, fue el sabio preceptor de mi inteligencia. Y no le debo únicamente ese servicio: él es también la salvaguardia de mi decoro, porque... ningún poderoso ha visto humillada mi cerviz.

En 1879 cuando murió un cajista de El Porvenir, se escribió por parte de sus compañeros de trabajo lo que a continuación citamos: ... él era para nosotros un modelo de hombre laborioso; él, por su sola superioridad que todos gustosamente reconocíamos, era el jefe del taller donde cumplíamos la ley del trabajo, para llevar honradamente el pan a nuestras familias. ... por eso nos lo hemos propuestos como modelo que difícilmente lograremos imitar. Acto seguido los empresarios escribieron lo siguiente: "El amigo íntimo, el joven leal, afectuoso y desinteresado que nos gloriábamos de tener por compañero... Bondad sin límites, clara inteligencia, honradez acrisolada, lealtad a toda prueba, carácter afabilísimo, constante laboriosidad, juicio recto, conocimiento de sus deberes y disposición para cumplirlos: tales fueron los dotes de nuestro querido amigo, tales fueron las cualidades que le atrajeron simpatías". Y luego los redactores del periódico

Palobrano. 9 Agosto/2008 
anotaron:

No sólo merecen loas los grandes hombres. También las merecen... los que en esfera de pequeño diámetro, los que en círculos más reducidos, luchan por medio de la inteligencia y el trabajo contra los rigores de la pobreza y el desamparo, y se abren paso a fuerza de privaciones muchas veces heroicas, hasta alcanzar en la sociedad el aprecio de cuantos les rodean, y los medios de derramar el bien en su tranquilo hogar. Por qué ha de echarse al olvido a los héroes del trabajo que como de la Barreda fueron constantemente virtuosos? ...

Leopoldo de la Barreda poseía una clara inteligencia, y había hecho algunos estudios que lo elevaron a un nivel superior al común....

Por carácter y educación era esclavo del deber: comprometido a llenar alguno, podía descansarse en su palabra porque ningún interés, ninguna fuerza habría podido apartarlo de su cumplimiento. ${ }^{17}$

El obituario de Francisco de Borja Ruiz rezaba: El incansable y modesto obrero en el famoso arte de Gutemberg, el decano de los impresores de la ciudad... La empresa de El Porvenir lamenta su desaparición... estimándola como una desgracia para el progreso del país en la propagación de las luces.... Cuando murió Domingo González Rubio la corona fúnebre señaló: Todo en él era modesto, su traje, su albergue, su mesa; y siempre lo vi, haciendo prodigios de economía. Con El Promotor pudo hacerse rico, pero no quiso explotar las ventajas de su posición, y prefirió consagrarse a sus propios ideales, estimular todas las empresas benéficas, todos los esfuerzos generosos, y brindar apoyo a los jóvenes que querían ejercitarse en las tareas de la prensa. ${ }^{18}$

De igual manera, un cronista de Barranquilla describía a un tipógrafo del último cuarto del siglo XIX como un hombre, ...extremadamente honrado, magnifico padre de familia y trabajador que le hizo gran bien a la sociedad con su tipografía... que era además centro de cultura social y venta de libros escogidos... Cobraba muy poco, se contentaba con poca ganancia. ${ }^{19}$ Otro tipógrafo, Carlos Gastelbondo Navas, nacido en Cartagena en 1873 y radicado en Barranquilla desde finales de ese siglo, ciudad en la que abanderó las iniciativas en pro de la organización obrera y artesanal divulgadas desde las páginas de su periódico El Progreso (fundado en 1904), se ganó el aprecio de todos los sectores de la población, al vérsele como, Hijo de su propio esfuerzo sin más ayuda que su talento claro y sus sentimientos elevados..., y otros lo veían como un,

Trabajador incansable, es todo lo que se llama un hombre práctico, de esos que estudian más sobre las cosas que sobre los libros, de los que saben dirigir sus esfuerzos por el camino de los hechos sin dejarse extraviar por engañosas teorías... Es prueba viva de cuanto es capaz el propio esfuerzo asociado a la austeridad de las costumbres y a la 
voluntad inquebrantable de surgir... Hombre de acción y de nobles ambiciones, ha ejercitado sus fuerzas y sus intelectos en labrarse una posición y en crearse un nombre...

Solo... sin ayuda de nadie... Gastelbondo ha subido, no a saltos sino peldaño por peldaño, la escala del verdadero mérito, de aquel que consiste en adquirir el aprecio social y en ganarse la vida de un modo independiente. Las credenciales de Gastelbondo son... las ejecutorias de la honradez, del trabajo, de las buenas costumbres, de su buen sentido y de la cultura...

Caso similar lo fue el también tipógrafo y pedagogo cartagenero Federico Núñez González-Rubio: Al lado de su padre aprendió a manejar el componedor que legara Gutemberg al progreso de los pueblos; y en ese trabajo cotidiano, en la lucha del pensamiento contra el oscurantismo... surgió el pedagogo sin pedantería y el hombre ilustrado sin fatuidad de necios. ${ }^{20}$

Este ideario político de autoestima social estuvo acompañado por otro que subrayaba la valoración de la educación y del trabajo, concebidos como el único factor de progreso individual y social y elemento determinante de la estimación de los demás. ${ }^{21}$ Los testimonios nos presentan a los tipógrafos como personas que tenían en alta consideración la lectura y la educación, siendo algunos talleres centros de sociabilidad cultural y política en los que se difundían y discutían las lecturas que circulaban de mano en mano. Algunos artesanos se convirtieron en una especie de librepensadores, en lo que el historiador inglés Eric Hobsbawm llamó "ideólogos del pueblo llano" en un artículo dedicado a los zapateros políticos europeos del siglo XIX. Con colecciones de periódicos, folletos, revistas, libros, afiches, carteles, literatura de folletín, etc., era usual que a muchos talleres artesanales concurrieran personas de diversa extracción social, interesadas en el diálogo, en el intercambio de ideas con artesanos interlocutores que llamaban la atención por sus expresiones iconoclastas y por sus apuntes picantes sobre la cotidianidad. ${ }^{22}$ Muchas familias de artesanos diseñaron estrategias de superación, mediante las cuales los miembros mayores se esforzaron por hacer de algunos de los menores, profesionales e institutores. En 1910 el joven médico Eduardo Miranda Fuentes respondía a sus detractores que lo menoscababan por sus origen humilde, lo siguiente: Hónrome de no proceder de las clases encumbradas... procedemos de esa modesta sociedad cartagenera, que afrontando toda clase de sacrificios hace prodigios de esfuerzos nada comunes. Mi familia es la única que en estos últimos tiempos ha dado tres doctores... ${ }^{23}$

La autovaloración fue reforzada por el hecho de vivir autónomamente. Ello es significativo en una sociedad en la que la mayoría de la población estaba 


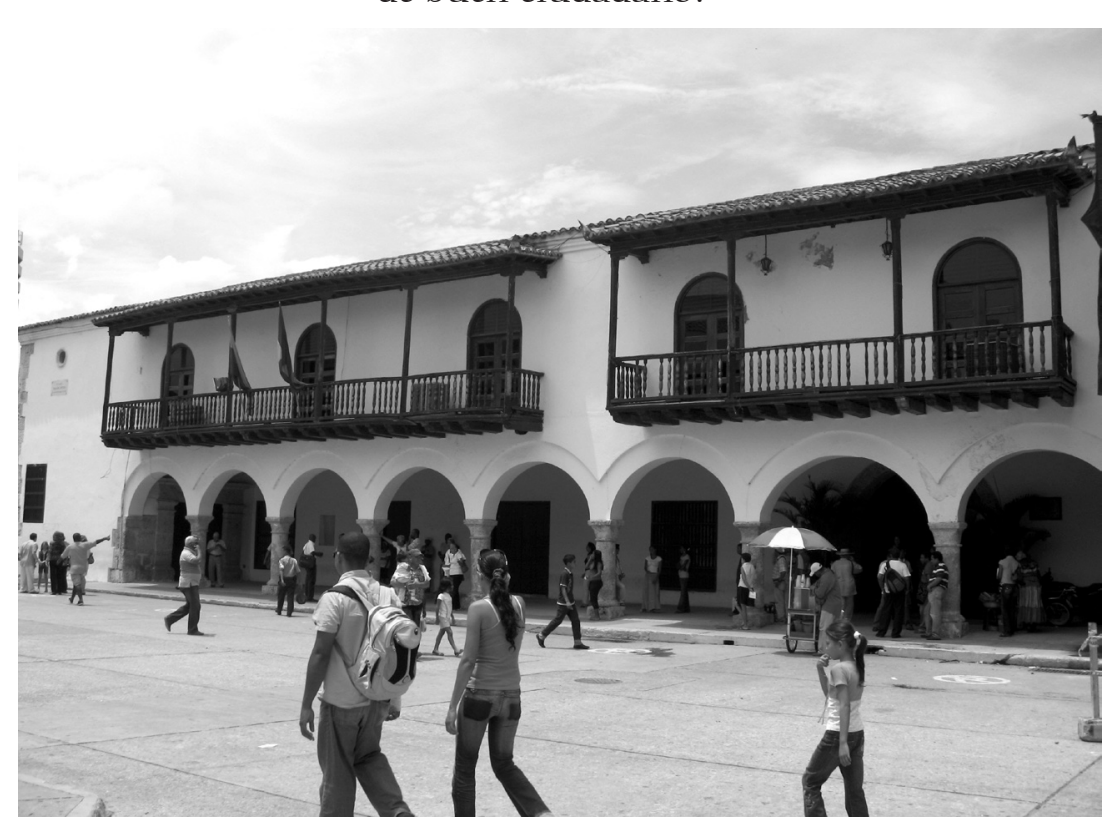

formada por jornaleros y por la servidumbre doméstica. Junto a estos existía un grueso número de pescadores, bogas, marineros, labradores, leñadores, considerados como los estratos más bajos, contra los que muchas veces se emitieron disposiciones coercitivas para controlarlos, llegándose algunas veces al extremo del concertaje forzoso por libertinaje. Usualmente los artesanos se diferenciaron de estos sectores, aunque muchas veces aparecieran como sus voceros; el mismo discurso liberal-radical siempre tuvo como límite la audiencia entre los artesanos, al que consideraba el sector natural al que estaba dirigido. Otro factor diferenciador del artesanado con relación a los demás estratos bajos de la población era que la pobreza se llevaba con dignidad, estableciendo una clara distinción entre las limitaciones materiales (pobreza) y la miseria como un estado material y espiritual degradante, tal como lo anota Cosme, el personaje de la novela de José Félix Fuenmayor publicada en 1927.

Ahora bien, ese estilo de vida no fue patrimonio exclusivo de los tipógrafos, pues como se afirma en un artículo publicado recientemente, ${ }^{23}$ la valoración del trabajo, de la educación y de la independencia era patrimonio de muchos sectores de trabajadores de diversas condiciones étnicas. Artesanos notables, trabajadores calificados de las artes modernas (mecánica), empleados de casas comerciales y de empresas de transportes, profesionales de condición humilde, hombres letrados, pequeños comerciantes, burócratas, oficialidad de la fuerza pública, educadores, parientes pobres de las familias de las elites, trabajadores humildes y muchos más, formaron parte de este sector que compartió un estilo de vida organizado en torno a la valoración del honor, la dignidad, la condición de buen vecino y de buen ciudadano.

Hasta donde la investigación histórica nacional arroja luces los orígenes de este estilo de vida se remontan a la segunda mitad del siglo XVIII cuando sectores de mestizos, negros libres y blancos pobres comenzaron a presionar para que la dignidad humana no fuese medida solo con base en el rasero de la cuna de nacimiento, es decir, por la limpieza de sangre, la condición étnica blanca y por pertenecer a una familia prestante. Exigían estos 
sectores que al lado de estas formas tradicionales de prestancia social, también se valorara el esfuerzo personal y familiar de aquellos que llevaban una vida decorosa y construida con esfuerzos, con trabajo. Hijo de su propio esfuerzo, hijo del trabajo fueron expresiones muy comunes a lo largo del periodo comprendido en esta investigación para referirse a estas personas. Esos sectores participaron en la lucha por la república con la aspiración de conseguir los espacios que bajo el régimen colonial les costaba ingentes trabajos. La ciudadanía fue la aspiración que los motivó y bajo el diseño de estrategias personales y familiares, abrieron brechas al orden social para permitirse la movilidad social en un sentido muy preciso: salir del estado de indiferenciación social que supone el calificativo de plebe y ganarse un estatus de reconocimiento y de diferencia.

Las formas como se irradió ese estilo de vida entre muchos sectores de la población aún permanecen en las tinieblas. Sin embargo, si es relativamente fácil demostrar que la autoimagen mesiánica que poseían los tipógrafos era debido a que el imaginario ilustrado de los tipógrafos estuvo ligado a una concepción mesiánica, creyéndose los portaestandartes de una nueva cultura que llevaría al conjunto de la sociedad a mejorar su condición moral. En este sentido, los tipógrafos fueron los abanderados de unos esfuerzos dirigidos a reformar muchos aspectos de la cultura popular que consideraban en contravía con el anhelado estadio de la civilización, al contar con los medios más propicios para alcanzarlo, muchos de cuyos elementos compartían pero otros. No olvidemos que los tipógrafos constituyeron el grupo sociocupacional que de mejor manera expresaba lo que el historiador francés Michel Vovelle llamó la condición de intermediarios culturales, es decir, era un grupo que por sus relaciones con los sectores letrados se encargaba de movilizar elementos de la cultura de los de arriba hacía los de abajo. ${ }^{25} \mathrm{La}$ revisión de periódicos de origen artesanal en cuya edición los tipógrafos tenían un protagonismo de primer orden, muestra la constante publicación de artículos que insistían en la necesidad de valorar el trabajo, la educación, la independencia y la temperancia. ${ }^{26}$

Durante varios decenios muchas familias se apertrecharon en esa escala de valoraciones sociales y defendieron sus estatus sociales frente a la nueva prestancia por riqueza material, a la que siempre contraponían lo que consideraban el mayor patrimonio de cualquier ser humano: dignidad, honradez, esfuerzo familiar, trabajo, estudio, decoro, el no escandalizar a la sociedad. Así se conservaron con orgullo y altivez, sin someterse y sin aceptar afrentas. Otras que formaban la franja de los parientes pobres de las elites, vivieron con unas prestancias prestadas y a la sombra de sus consanguíneos colaterales, y se caracterizaron por su arribismo y por sus 
actitudes ofensivas frente a los demás, y constituyeron un baluarte en la defensa de la prestancia por nacimiento. Muchas otras cayeron en desgracia y trasegaron de la pobreza a la miseria sin oponer tenaz resistencia, estados que marcaban una diferencia significativa en una época en la que con mucha vergüenza algunos sectores aceptaban ser declarados pobres de solemnidad para poder recibir una pequeña ayuda de las autoridades y así evitar caer en la condición de miserables, el último peldaño de la estratificación social.

Ya para el decenio de 1920 se asistió a una degradación del estilo de vida preconizado por los tipógrafos y otros sectores de artesanos notables debido a la conjunción de varias circunstancias, entre las que sobresalen las transformaciones que sufrió el oficio de la tipografía debido al surgimiento de nuevas tecnologías, a la separación entre la labor de editor de periódicos y quienes lo imprimían y al acentuamiento de la diferenciación social que vivió la sociedad colombiana durante los años de la prosperidad a debe, cuando se produjo una movilidad social fundada en la riqueza material.

En fin, para el decenio de 1920 ya no estamos frente a un artesanado tradicional pues los niveles de calificación de la mano de obra, la intensidad del trabajo y las formas de remuneración, entre otras, han variado aunque continúen los moldes del trabajo manual. Además, el incremento del número de ejercitantes de los oficios manuales así como el avance de la economía de mercado, han producido al artesano chapucero, surgiendo un gran número de talleres y de pequeños sitios de trabajo, como también al zapatero ambulante por las calles de las ciudades con su pequeña caja de herramientas. Por otra parte, en la mayoría de los oficios (con excepción de algunos sectores de sastres, herreros, mecánicos y maestros de obras) la calificación de la mano de obra era baja debido a que sus producciones estaban destinadas a sectores de escasos ingresos ${ }^{27}$. Hubo tendencias a la proletarización en algunos oficios que como en el caso de los alfareros, tejedoras, tabaqueras, dobladoras de tabaco, molenderas y cafeteras, presenciaron el surgimiento de establecimientos manufactureros tales como las fábricas de objetos de aluminio y de hierros colado, las textileras, las cigarreras, los molinos de cereales y de café y las manufacturas de materiales de construcción.

En el caso de la tipografía un factor que incidió en la diferenciación interna del gremio fueron los avances técnicos que se introdujeron en la región como el linotipo, lo que hizo más fácil el trabajo, desapareciendo algunos privilegios que tenían los tipógrafos más viejos de acuerdo con sus conocimientos y pericias. El tipógrafo Germán Maciá en 1919 pedía a la Unión Tipográfica que reglamentara el ejercicio del oficio, pues, ... jóvenes que ni siquiera tienen nociones de ortografía 
y desconocen por completo las más rudimentarias reglas del patrio idioma, son equiparados por el patrón, y remunerados por él, a la par del más experto y antiguo y distinguido cajista, concluyendo que se debía establecer categorías ocupacionales en ese arte. En ese año el surgimiento de la publicación de este gremio se debió básicamente al apremio de defender el oficio; en su primer editorial se señala que el propósito de aquélla agremiación era el defender el ... gremio tipográfico de Cartagena, que viene cada día sufriendo amargos quebrantos; y esto se debe, por una parte, al desdén con que se mira a dicho arte....28

\section{BIBLIOGRAFIA}

Fuentes de archivos, memorias, directorios comerciales, compilaciones documentales:

ÁLVAREZ, Jesús y URIBE, María T. (1984). Índice de prensa colombiana 18401890. Universidad de Antioquia, Medellín.

Archivo Catedral de Cartagena. (1898). Carta pastoral del Ilustrísimo Sr. Dn. Pedro Adán Brioschi al pueblo y clero de la Diócesis de Cartagena, tip. Salesiana. Bogotá.

Archivo Histórico del Atlántico. (1905), Fondo notarial, Libro tomo III. Barranquilla.

Boletín Historial. (1918). Nos 37-38, Academia de Historia de Cartagena, Cartagena.

Catálogo de Publicaciones seriadas siglo XIX. (1995), tomo I. Bogotá, Biblioteca Nacional de Colombia-Colcultura. Cartagena.

CORONEL, Juan. (1944). Un peregrino, Oficina de Extensión Cultural. Cartagena.

CORRALES Manuel Ezequiel (comp.). (1884). Efemérides y anales del Estado Soberano de Bolívar, tomo 2. imp. de J. J. Pérez. Bogotá.

Diario de Bolívar. $(1877,1878)$. Cartagena.

Diario del Comercio. (1925). Barranquilla.

El Anunciador. (1922). Barranquilla.

El Artesano. (1850). Cartagena.

El Churiador (1849). Santa Marta.

El Grito de la Democracia (1910). Cartagena. 
El Porvenir. (1879, 1882, 1893, 1904, 1909, 1910, 1911, 1913). Cartagena.

El Progreso. (1906, 1912). Barranquilla.

El Tipógrafo. (1919) º 2, Unión Tipográfica. Cartagena.

Gaceta de Boltvar. (1872). Cartagena.

Hemeroteca Luís López de Mesa. Catálogo general, vol. I. Banco de la República, s.f. Bogotá.

Informe del secretario de gobierno al gobernador del departamento. (1924). imp. Departamental. Cartagena.

Informe del gobernador de Bolivar a la asamblea departamental. (1929). imp. Departamental,. Cartagena.

La Democracia. (1850). Cartagena.

La Prensa. (1931). Barranquilla.

La Tribuna. (1915). Cartagena.

La Unión Comercial. (1915). Cartagena.

LEMAITRE, Alberto. (s.f.). Estampas de la Cartagena de ayer, Cartagena, s.p.i.

LEMAITRE, Daniel. (1984). Poesías y corralitos de piedras, Bogotá, Corporación Financiera del Norte.

Penitente. (1910). Cartagena.

RAMIRO Don. (1928). Mis entrevistas, s.p.i. Barranquilla.

RASCH SILVA, Enrique. (1910). Guía comercial de Barranquilla, imp. El Conservador. Barranquilla.

Registro de Bolívar. (1897). Cartagena.

URUETA José y GUTIÉRREZ DE PIÑERES Eduardo. (1912). Cartagena y sus cercanías, Imp. Departamental. Cartagena.

Libros:

AGUILERA Miguel. (1959). Lácides Segovia (un carácter), ed. ABC, 1959. Bogotá.

BERMÚDEZ B. Arturo. (1981). Materiales para la historia de Santa Marta. Banco Central Hipotecario. Bogotá. 
BURKE, Meter. (1991). La cultura popular en la Europa moderna, Alianza ed. Madrid.

CHARTIER, Roger. (1993). Libros, lecturas y lectores en la edad moderna, Alianza ed. Madrid.

DE LA VEGA Fernando. (1937). Cartagena, la de los claros varones, ed. El Mercurio. Cartagena.

GÓMEZ OLACIREGUI, Aureliano. (1967), Prensa y periodismo en Barranquilla, eds. Otto Lalemand. Barranquilla.

HOBSBAWM, Eric. (1979) El mundo del trabajo, ed. Crítica. Barcelona.

MEDINA, Toribio de. (1904), La imprenta en Cartagena de Indias (1809-1820), imp. Elzeviriana. Santiago de Chile.

MENDOZA Cesar y BOHÓRQUEZ Martha. (1996). "La prensa en Barranquilla a mediados del siglo XIX", en Historia Caribe, No 2, Universidad del Atlántico. Barranquilla.

PORTO DEL PORTILLO, Raúl. (1943). Los próceres de Cartagena, vol. 2, Imp. Departamental. Cartagena.

RESTREPO Pastor (1994). Genealogías de Cartagena de Indias, Instituto Colombiano de la Cultura Hispánica. Bogotá.

REVOLLO Pedro M. (1850). Mis memorias, Ed. Mejoras. Barranquilla.

RULE John (1993). Clase obrera e industrialización 1750-1850, ed. Crítica. Barcelona.

SOLANO, Sergio P. (1996). "Trabajo y ocio en el Caribe colombiano 1880-1930", en Historia y cultura № 4, Universidad de Cartagena, págs. 61-76. Cartagena.

(2003). Puertos, sociedad y conflictos sociales en el Caribe colombiano, 1850-1930, Observatorio del Caribe Colombiano-Universidad de CartagenaMinisterio de Cultura. Cartagena.

SOLANO, Sergio Paolo y FLÓREZ, Roicer. (2008), "Del texto al contexto. Cosme y la sociedad urbana costeña a comienzos del siglo XX", en Cuadernos de literatura del Caribe e Hispanoamérica, No 7, Universidad del Atlántico-Universidad de Cartagena, pp. 173-217. Barranquilla.

RODRÍGUEZ, Pablo. (2002). En busca de lo cotidiano. Honor, sexo, fiesta y sociedad siglos XVII-XIX. Universidad Nacional. Bogotá.

VOVELLE, Michel. (1985). Ideología y mentalidades, ed. Ariel. Madrid. 
ZEMON DAVIS, Natalie. (1993). Sociedad y cultura en la Francia moderna, , ed. Crítica. Barcelona.

\section{BIOGRAFIA}

Licenciado en Ciencias Sociales y Económicas de la Universidad del Atlántico. Candidato a Magíster en Historia, convenio Universidad de Cartagena-UPTC de Tunja. Profesor Asociado del Programa de Historia, Facultad de Ciencias Humanas de la Universidad de Cartagena. e-mail: sergiopaolosolano@yahoo.es / ssolanod@unicartagena.edu.co

\section{NOTAS AL PIE}

(*) Este artículo es resultado del proyecto de investigación Trabajadores y cultura en el Caribe colombiano, 1850-1930, el que forma parte de la línea de investigación en Historia social urbana del grupo de investigaciones Frontera, sociedad y cultura del Programa de Historia, Facultad de Ciencias Humanas, Universidad de Cartagena.

1 ZEMON DAVIS Natalie (1993), "La imprenta y el pueblo", en Sociedad y cultura en la Francia moderna, Barcelona, ed. Crítica, 1993, pág. 186-224; CHARTIER, Roger (1993), Libros, lecturas y lectores en la edad moderna, Madrid, Alianza ed.

2 Sobre la primera imprenta en Cartagena, la de Diego Espinosa de los Monteros ver MEDINA Toribio de (1904), La imprenta en Cartagena de Indias (1809-1820), Santiago de Chile, imp. Elzeviriana.

${ }^{3}$ Catálogo de publicaciones seriadas siglo XIX, tomo I, Bogotá, Biblioteca Nacional de ColombiaColcultura, 1995. Salvo que se señale, todas las referencias que en adelante se haga a imprentas se extraerán de esta fuente, de Hemeroteca Luís López de Mesa. Catálogo general, vol. I. Bogotá, Banco de la República, s.f. y ÁLVAREZ Jesús y URIBE María T. (1984), Índice de prensa colombiana 1840-1890, Medellín, Universidad de Antioquia. "Cuadro estadístico que expresa el movimiento de los periódicos que han visto la luz en el Departamento de Bolívar durante los años de 1910-1928", en Informe del gobernador de Bolívar a la asamblea departamental, Cartagena, imp. Departamental, 1929.

${ }^{4}$ BERMÚdEZ Arturo (1981), Materiales para la historia de Santa Marta. Bogotá, Banco Central Hipotecario, pág. 197-199; también ver ALARCÓN M. Luís, "Imprentas y periódicos en Santa Marta durante el siglo XIX", en Revista dominical El Heraldo, Barranquilla, octubre 18 de 1992; sobre la introducción de la prensa en Barranquilla, ver GÓMEZ OLACIREGUI Aureliano (1967), Prensa y periodismo en Barranquilla, Barranquilla, eds. Otto Lalemand; MENDOZA Cesar y BOHÓRQUEZ Martha (1996), "La prensa en Barranquilla a mediados del siglo XIX", en Historia Caribe, No 2, Barranquilla, Universidad del Atlántico.

5 "Periódicos que se editan en la provincia de Cartagena", en Registro de Bolívar, Cartagena, abril 24 de 1897. Los datos de 1886 y 1912 pueden consultarse en URUETA José y GUTIÉRREZ de PIÑERES Eduardo (1912), Cartagena y sus cercanías, Cartagena, Imp. Departamental, pág. 95-96.

6 "La corrección de pruebas", en El tipógrafo, № 2, Cartagena, Unión Tipográfica, 1919.

7 "Informe del señor Alcalde del Distrito de Cartagena" (1924), en Informe del secretario de gobierno al gobernador del departamento 1924, Cartagena, imp. Departamental, pp. 32-33. RASCH SILVA Enrique (1910), Guía comercial de Barranquilla, Barranquilla, imp. El Conservador. En 1912 la Tipografía Mogollón contaba con 60 operarios. URUETA J. y GUTIÉRREZ E., Cartagena y sus cercanías, pág. 97.

8 "Bartolomé Calvo", en El Porvenir, Cartagena, agosto 24 de 1909; "Bartolomé Calvo encarna... eso que se ha llamado "el propio esfuerzo", la sublimación de la voluntad para triunfar... en sus 
mocedades tomó el chibalete del tipógrafo y desplegó en el taller las energías de su brazo... De la anonimia del obrero salió el periodista". VEGA Fernando de la (1937), Cartagena, la de los claros varones, Cartagena, ed. El Mercurio, pág. 94-95.

9 PORTO DEL PORTILlO Raúl (1943), Los próceres de Cartagena, vol. 2, Cartagena, Imp. Departamental, pág. 221-22.

9 RESTREPO Pastor (1994), Genealogías de Cartagena de Indias, Bogotá, Instituto Colombiano de la Cultura Hispánica; J. URUETA y E. GUTIÉRREZ de P., Cartagena y sus cercanías, pp. 95-98; "Tipografía de Antonio Araujo", en Gaceta de Bolívar, Cartagena, diciembre 6 de 1872.

10 "Periódicos que se editan en la provincia de Cartagena", en Registro de Bolívar, Cartagena, abril 24 de 1897. PORTO R., Los próceres de Cartagena, Op. Cit., vol. 2, pp. 211-213. CORRALES Manuel Ezequiel (comp.) (1884), Efemérides y anales del Estado Soberano de Bolívar, tomo 2, Bogotá, Imp. de J. J. Pérez, pp. 104-105. "Federico Núñez G.", en El Porvenir, Cartagena, octubre 12 de 1893 y julio 10 de 1910.

11 "Hombres notables de Cartagena. Gabriel E. O’Byrne", en El Porvenir, Cartagena, mayo 26 de 1913; CORONEL Juan (1944), Un peregrino, Cartagena, Oficina de Extensión Cultural. AGUILERA Miguel (1959), Lácides Segovia (un carácter), Bogotá, ed. ABC.

${ }^{12}$ El Tipógrafo, № 1, Cartagena, Unión Tipográfica, 1919.

13 "General Aurelio de Castro", en Diario del Comercio, Barranquilla, febrero 6 de 1925.

14 "Doctor Antonio Regino Blanco", en Boletín historial, Nos 37-38, Cartagena, Academia de Historia de Cartagena, 1918, pág. 169.

${ }^{15}$ CORONEL J., Un peregrino; un concepto de igual tenor puede leerse en El Churiador, Santa Marta, febrero 18 de 1849. Otros sectores de menestrales reconocían el papel de la imprenta para garantizar su independencia y su dignidad de hombres libres. El Artesano, Cartagena, febrero $1^{\circ}$ de 1850.

16 “Leopoldo de la Barreda”, en El Porvenir, Cartagena, agosto 17 de 1879.

17 "Domingo González R.", y "Duelo", en El Porvenir, Cartagena, enero 15 de 1904 y abril 10 de 1882.

${ }^{18}$ REVOLLO Pedro M. (1850), Mis memorias, Barranquilla, ed. Mejoras, pág. 68.

19 "Andando" y "Carlos Gastelbondo", en El Progreso, Barranquilla, octubre 20 de 1912; "Progreso", "Independencia de las tradiciones retrógradas" y "El honor y el sacrificio, móvil y norma e nuestra conducta social", en La Democracia, Cartagena, mayo 2, 9 y 16 de 1850. "Las ventajas de un oficio", en El Progreso, Barranquilla, octubre 22 de 1906. "Federico Núñez G.", en El Porvenir, Cartagena, julio 12 de 1910.

${ }^{20}$ El periódico La Democracia, en 1850 criticaba la aversión al trabajo material, anotando que el amor a éste traía como recompensa las comodidades y las virtudes. Un periódico de tendencia liberalsocialista publicado en Barranquilla en 1921 también está lleno de loas al trabajo, concibiéndolo como una condición inmanente al hombre, creador de riquezas, de bienestar y eje del desarrollo de una moral propicia para el progreso. "Escuelas y talleres", en La Democracia, Cartagena, febrero 14 de 1850. La permanencia de estas ideas pueden verse en: "Por la reacción de la unión obrera", en El Progreso, Barranquilla, mayo 11 de 1912; "Justicia al mérito", en El Anunciador, Barranquilla, enero 16 de 1922; "Lo que debe saber el pueblo", en La Prensa, Barranquilla, marzo 26 de 1931. Algunas descripciones de tradiciones familiares artesanales aparecen en DON RAMIRO, Mis entrevistas, págs. 67, 136, 231 y 241; para el caso de Cartagena ver: "Artesanos y obreros"; "Política y trabajo"; "Moral tipográfica"; "El artesano", en El Porvenir, Cartagena, noviembre 16 y 27 de 1910; julio 22 de 1911; noviembre $1^{\circ}$ de 1913.

${ }^{21}$ LEMAITRE Daniel (1984), Poesías y corralitos de piedras, Bogotá, Corporación financiera del Norte, pp. 233-234; LEMAITRE Alberto (s.f.), Estampas de la Cartagena de ayer, p. 44; HOBSBAWM Eric

Palobrano. 9 Agosto/2008 
(1979), El mundo del trabajo, Barcelona, ed. Crítica, págs. 144-184.

22 "Nuestra misión", en El Grito de la Democracia, Cartagena, marzo 9 de 1910; "Me defiendo", en Penitente, Cartagena, julio 31 de 1910; “Necrología”, en El Porvenir, Cartagena, enero 22 de 1904.

23 SOLANO Sergio Paolo y FLÓREZ Roicer (2008), "Del texto al contexto. Cosme y la sociedad urbana costeña a comienzos del siglo XX", en Cuadernos de literatura del Caribe e Hispanoamérica, $N^{\circ}$ 7, Barranquilla, Universidad del Atlántico-Universidad de Cartagena, pp. 173-217. Para el caso de la prestancia de ciertos oficios de la navegación fluvial a vapor por el río Magdalena ver SOLANO Sergio Paolo (2003), Puertos, sociedad y conflictos sociales en el Caribe colombiano, 18501930, Cartagena, Observatorio del Caribe Colombiano-Universidad de Cartagena-Ministerio de Cultura, págs. 55-78.

24 VOVELLE, Michel (1985), Ideología y mentalidades, Madrid, ed. Ariel. Sobre los movimientos europeos encaminados a reformar la cultura popular ver BURKE Peter (1991), La cultura popular en la Europa moderna, Madrid, Alianza ed., pág. 293 y ss.

${ }^{25}$ El artesano editado en 1850 en Cartagena por el tipógrafo Francisco de Borja Ruiz, La voz del artesano editado en 1898 en Barranquilla por Victoriano Cabrera, La voz del pueblo editado en Cartagena en 1909 por la Sociedad de Artesanos de Cartagena, Penitente editado desde 1908 en esta misma ciudad por el tipógrafo Clemente López. SOLANO Sergio Paolo (1996), "Trabajo y ocio en el Caribe colombiano 1880-1930", en Historia y cultura № 4, Cartagena, Universidad de Cartagena, págs. 61-76.

${ }^{26}$ Caso parecido había sucedido en Inglaterra. RULE John (1993), Clase obrera e industrialización 1750-1850, Barcelona, Ed. Crítica.

${ }^{27}$ En carta que este tipógrafo dirigió a la directiva de su gremio, afirmó: "Desde mi aprendizaje hice del arte una especial distracción a mi vida, no sólo como medio de recursos para la lucha por la vida, como de escuela y algo más que mis pocas facultades literarias no alcanzan a nombrar..." El Tipógrafo, № 1. Cartagena, Unión Tipográfica, 1919. 